\title{
Park and ride trips to work in the city of Sao Paulo
}

\author{
A. B. Lima ${ }^{1} \&$ J. Waisman ${ }^{2}$ \\ ${ }^{1}$ Department of Transportation Engineering, São Paulo Metro Co., \\ Escola Politécnica da Univesidade de São Paulo, Brazil, \\ ${ }^{2}$ Department of Transportation Engineering, Sistran Engenharia, \\ Escola Politécnica da Univesidade de São Paulo, Brazil
}

\begin{abstract}
This paper relates to the analysis of characteristics of trips and users who drive their car to the stations of the high capacity passenger transport system, in which they embark and continue the trip to their workplace. We study this type of trip related to the accessibility of downtown and with the quality of car parking facilities next to the stations and at the workplace. The transport data within the Metropolitan Region of Sao Paulo presents information about these trips, known as Park and Ride, on the subway lines. Parking at stations, trip pattern characteristics and users' socioeconomic status were studied. The user behaviour was analyzed in order to model choice between going directly by car to the workplace or going by car to the station and taking the subway to the workplace. A discrete choice model was proposed based on the random utility theory. The variables considered are the difference in total travel times, the difference in parking prices and the quality of parking next to the station. A binomial logit model was considered and a stated preference survey was conceived. A case study was conducted and users of a car parking lot next to the subway at Tiete Station were interviewed. The results of the interviews were used to calibrate and compare the discrete choice models tested. It was verified that the difference in total travel times between the alternatives is more important than the difference in parking prices in transport mode choice decision making. It was also verified that quality is significant to users, and it is seen as higher when parking is inside the metro station building. This is probably due to time savings and both comfort and safety.
\end{abstract}

Keywords: transport, subway, station, park and ride. 


\section{Introduction}

In the last 40 years, the São Paulo Metropolitan Region (19 million inhabitants) went through deep changes socially, in its economy, land use and transport structure. This process showed slowing population growth rates. The central areas (CBD) lost population, while growth rates in the peripheral areas were above the regional average. Industrial employment has continuously decreased and has now reached $20 \%$ of the total jobs, followed by an intense and disperse growth of commerce/services activities. Formal jobs, around $40 \%$ of the total, were surpassed by third party services and informality. The female share in the work market has reached almost $50 \%$ of the total jobs, and women are responsible for the support of one third of the region's households.

Private auto ownership has spread everywhere, becoming accessible to all income levels of the population. The car ownership rate went from 70 per 1000 inhabitants in 1967 to 200 per 1000 inhabitants in 2007. The street network has continuously expanded, mainly outside the central area and some perimetric connections were implemented. The modal split has shifted from $32 \%$ of auto daily trips (in 1967) to 52\% (in 2007). As a consequence, social and economic costs are increasing and quality of life is decreasing.

Work trip destinations are clearly oriented towards the $\mathrm{CBD}$ and its surroundings, giving rise to traffic jams during peak hours and low average speeds. On the other hand, these areas show the worst records of both environmental pollution and noise.

The CBD and its surroundings are well served by subways, commuter trains, buses and trolleybus services, but existing parking spaces contribute to attracting car users. There are public and private parking lots and also sponsored (free) parking and some on-street parking. In fact, recent surveys show 65.000 auto daily trips towards this area.

Auto and subway integration was planned during the construction of the first subway line (1976) and few parking lots were constructed within the stations, but gradually these actions were discontinued. Some parking lots exist around the metro stations; they are run by private entrepreneurs without any coordination with public transport authorities. Nevertheless, subway data show the event of 30.000 daily auto + subway trips, where $65 \%$ are for work and 7.000 work trips by auto + subway towards the CBD are observed daily (CMSP [1]).

\section{Objectives}

This paper is intended to:

- $\quad$ present the characteristics of both work trips and users who drive their auto to a subway station, park their vehicle there and board the subway towards their final destination in the CBD;

- analyse auto + subway users' behaviour in daily work trips towards the CBD; and

- evaluate this kind of trip (auto + subway) and formulate alternatives to emulate them. 


\section{Data collection}

Trip patterns and the socioeconomic status of auto + subway users travelling to work in the CBD were obtained from a field survey conducted at one of the subway network stations (Tiete station) (Lima [2]).

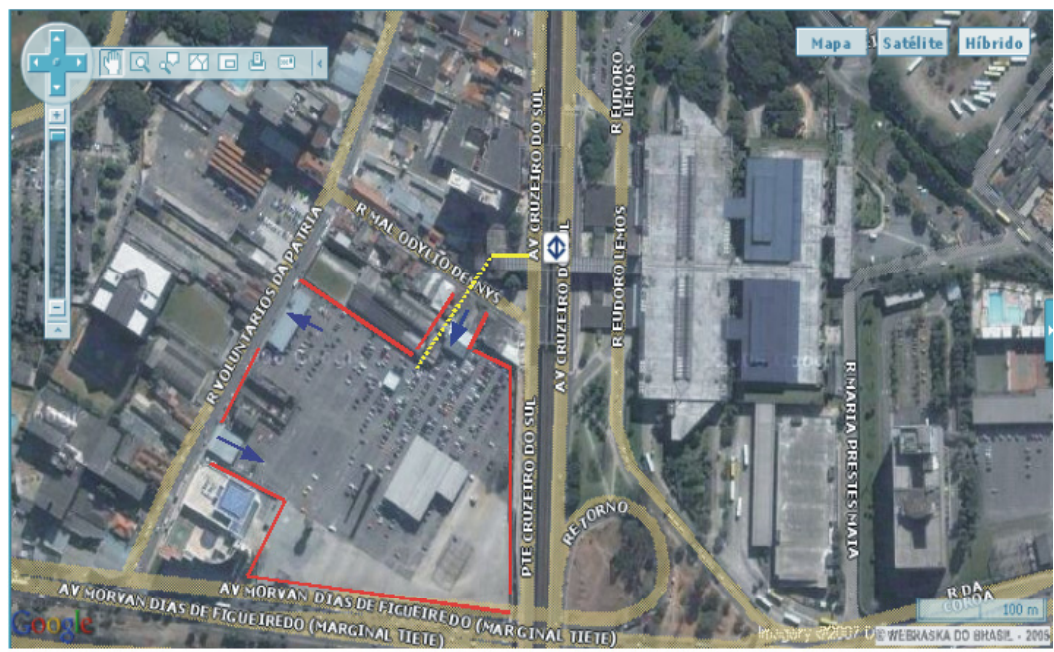

$\rightarrow$ Vehicle access — Parking lot limits _ Walking path to station

Figure 1: Parking lot location besides Tiete station.

Data collected was also intended to analyse and evaluate total travel time, parking prices and parking quality influences on users' behaviour.

The data sheet applied comprised three sections: one for users socioeconomic information (age, gender, instruction, occupation, family income and car ownership), the second for trip patterns (trip origin, destination and duration; main reasons for choosing this auto + subway trip), and the last for questions about stated preference.

Questions about stated preference presented the description of simultaneous situations of travel times differences "going by car" or "going by auto + subway", parking price differences either at the subway station or at the CBD and parking quality understood as parking inside the station building (good quality) or parking outside the station building (bad quality).

Travel time differences were expressed through four levels: no difference, more than 15 minutes, more than 30 minutes, or more 45 minutes going by car.

Monthly parking expenditure at the subway station was of R $\$ 80,00$ (US\$ $50.00)$. Monthly parking expenditure at the CBD was expressed through four levels: $\mathrm{R} \$ 40,00$ (US\$ 25.00), R $\$ 80,00$ (US\$ 50.00), R \$ 160,00 (US\$ 100.00) and $\mathrm{R} \$ 320,00$ (US\$200.00). 
The field survey was performed during the peak hours of two weekdays and 109 valid questionnaires were obtained. The parking lot where the survey was performed is located outside the station building, is easily accessible by cars and demands a 2,5 minute walk for users to reach the subway boarding platform.

\section{Users' and trip characteristics}

Users' and trip characteristics can be described by the following results from the survey with daily commuters:

- $\quad 61 \%$ of those interviewed work in the CBD and $63 \%$ are male;

- $\quad 72 \%$ of those interviewed are aged between 19 and 45 years and $76 \%$ have a college education;

- $\quad 73 \%$ of those interviewed are formal workers, $99 \%$ own their auto and have an average monthly family income of R $\$ 5.400,00$ (US\$ $2.200,00$ );

- for $58 \%$ of those interviewed, the auto + subway total travel time is smaller than the auto total travel time; for $9 \%$ it is the same;

- $\quad$ average total travel time for auto + subway is $71,5 \mathrm{~min}$. and for the auto it is $78 \mathrm{~min}$;

- $\quad 78 \%$ of those interviewed classify their parking conditions at Tiete station as very good/good; subway services are very good/good for $60 \%$ and access to the CBD by car is very bad/bad for $88 \%$;

- users value parking characteristics according the following topics: safety $(29 \%)$, ease of vehicle access $(21 \%)$, walking distance to subway station of less than $100 \mathrm{~m}(19 \%)$, reduced fares $(16 \%)$; other $(15 \%)$.

\section{Users' behaviour and preferences}

Transport studies on users' behaviour and preferences are, generally, based on the theory of random utility. Theoretically (Williams [3]), individuals of a given homogeneous population act rationally and have perfect information of all available alternatives. This means they choose the alternative that maximizes their personal utility.

The concept of utility is used as an ordering theory, meaning that the individual looks after the best for himself. In order to forecast which alternative will be selected, his (her) utility value must be differentiated regarding other alternatives and valued as a probability between 0 and 1 .

In this paper, the approach applied considers the calibration of a binomial logit model from data obtained in a stated preference survey with users (Ortuzar [4]).

The adopted model has the following formulation:

$$
P(\text { auto })=\frac{1}{1+e^{\theta_{t} \Delta T+\theta_{c} \Delta C+\theta_{q} Q+\theta_{A+S}}}
$$

where 
$\Delta \mathrm{T}=$ the variable factor related to the difference of total travel times (minutes) between auto + subway and auto $\left(T_{A+S}-T_{A}\right)$

$\Delta \mathrm{C}=$ the variable factor related to the difference in monthly parking costs between the subway station and the CBD $\left(C_{A+S}-C_{A}\right)$

Q = the dummy variable for quality, being 0 for parking outside the station building and 1 for parking inside the subway station building

$\theta \quad=$ the utility weight for factors meaning the total travel time difference, parking costs and parking quality

$\mathrm{P}($ auto) $=$ the probability of going by car.

The parameter estimates for utility functions, being based on discrete choices, cannot be obtained through the use of regression techniques. As an alternative, the maximum likelihood technique is used. The quality evaluation of parameter estimates is done with indicators related to the parameters statistics and model performance measures.

The factorial design generated the alternatives format, i.e., $4 \times 4=16$ sets of choices, for each of the parking conditions ("inside" or "outside" the metro station building) and corresponding to the following question for example: "Which alternative would you choose if the car journey to the centre was 15 min. longer and the parking $R \$ 40,00$ cheaper?"

The interviewee has made his (her) choice among the alternatives for auto and auto + subway for all questions. All the interviews followed the same order of presenting the choice of alternatives; the factorial design ensured that all attribute effects are independent and it was observed that the last questions favour the choice of the auto + subway alternative.

The model estimation was based on data from 109 interviews with 16 possible choices, totalling 1.744 stimuli. There were 1.475 auto + subway choices and 269 car choices, including the levels that included dominant alternatives.

Three different mathematical models were obtained under the conditions of parking the car outside the subway station building (MODEL 1) and parking the car inside the subway station building (MODEL 2) and also when introducing a dummy variable for quality (MODEL 3). See Tables 1-3.

The parameter estimates for Models 1-3 present an adequate confidence level for all parameters, i.e., for all variables used. The adjustment quality for all models present values above the recommended indexes, i.e., between 0,2 and 0,4 .

The following step was to exclude the situation with higher parking prices at the CBD ( $\mathrm{R} \$ 320,00 / \mathrm{mo}$ ), which lead to the choice of car + subway as the dominant alternative. Although the number of stimuli is reduced, a small influence was observed on the model adjustment quality and on parameters confidence.

Repeating the same procedure, the situation of higher total travel times (more than 45 minutes) for car trips was also excluded, to avoid the car + subway as the dominant alternative. No significant changes in the results were observed. 
The comparison of results obtained for Models 1-3 related to the conditions of both total travel time and parking cost differences shows the following:

- $\quad$ user time values are R\$ 0,138/minute (US\$ 0.083/minute), R\$ 0,076/minute (US\$ 0.046/min) and R\$ 0,114/minute (US\$ 0.068/minute) for Models 1-3, respectively;

- for quality (Model 3), the equivalent monetary value is R\$ 26,75/month (US\$ $16.02 /$ month), meaning the willingness to pay this value monthly if parking is inside the subway station or face an additional travel time of $10,64 /$ minute. This value could also mean the "cost" of more comfort and safety.

Table 1: $\quad$ Model 1.

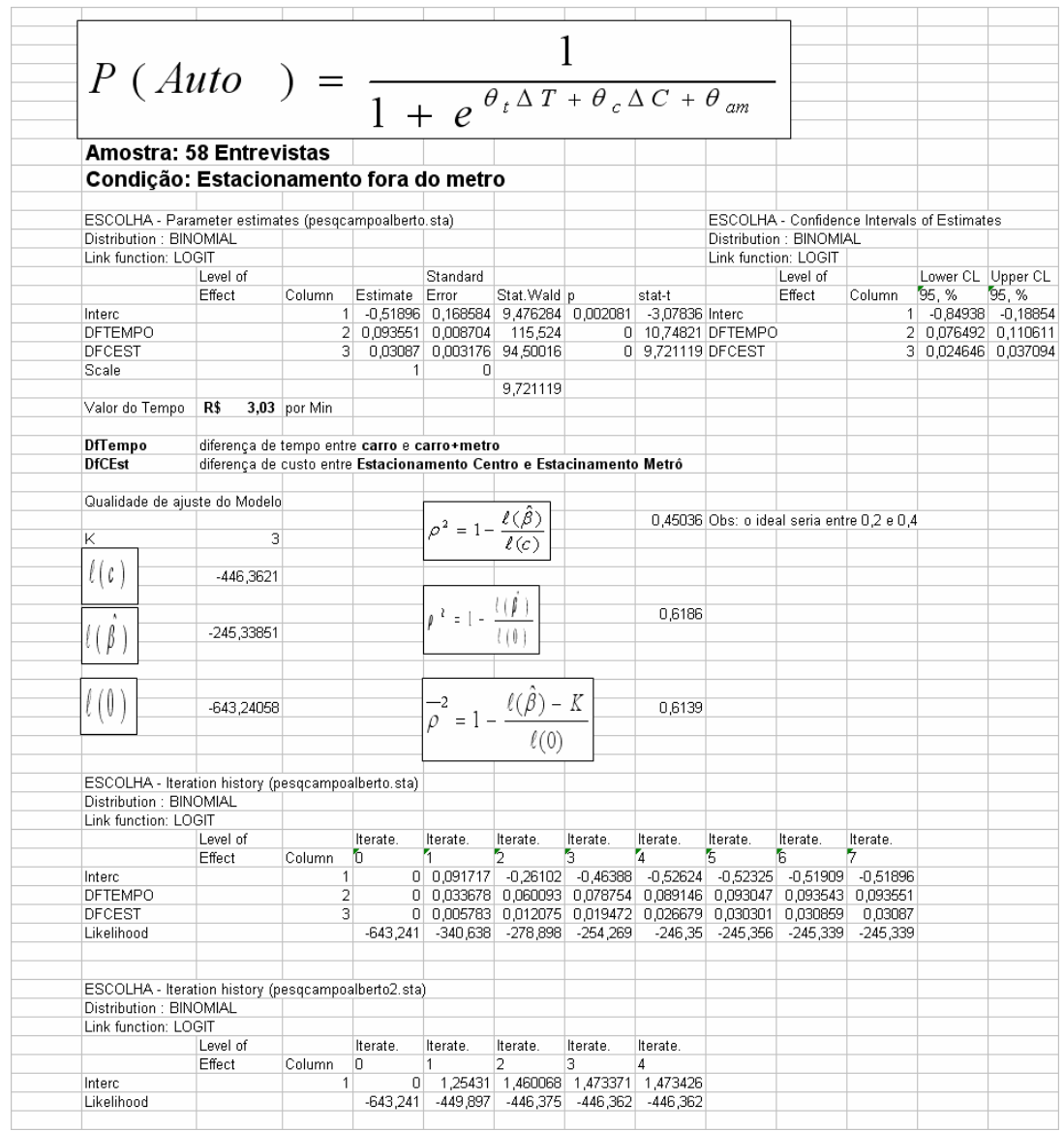

$$
\begin{aligned}
& \text { fora } \\
& P(\text { Auto })=\frac{1}{1+e^{0,094 \Delta T+0,031 \Delta C-0,519}}
\end{aligned}
$$


Table 2: $\quad$ Model 2 .

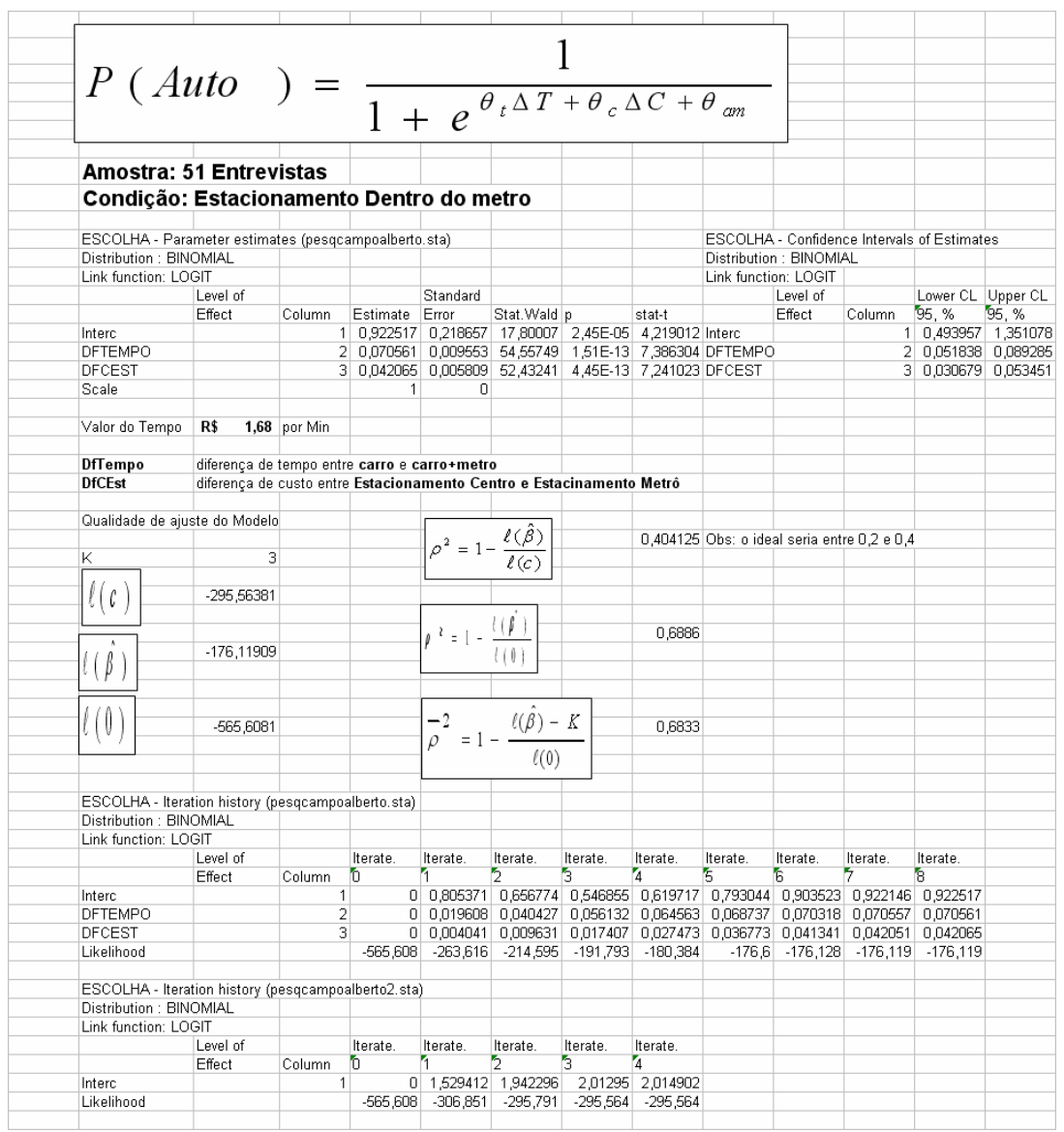

$$
\begin{aligned}
& \text { dentro } \\
& P(\text { Auto })=\frac{1}{1+e^{0,071 \Delta T+0,042 \Delta C+0,923}}
\end{aligned}
$$

\section{Conclusions}

Different simulations were made in order to evaluate the influences of both total travel times and parking price differences in users' choice. Some of the results are presented bellow.

- $\quad$ For Model 3: free parking at the CBD destination and the same total travel time for both alternatives leads to $95 \%$ of car trips and $5 \%$ of car + subway trips with parking outside the station. This record shows how relevant the influence of sponsored (free) parking is in users' decision making. On the 
other hand, when parking at the CBD destination is R\$ 80,00 (US\$ 50.00) more expensive than parking at the subway station, and the total travel time is the same, $91 \%$ or $98 \%$ of users choose the car + subway trip for parking outside or parking inside respectively;

- For Model 1: an increase of either 30 minutes in total travel times or R\$ $80,00 /$ month (US\$ 50.00/mo) in parking expenditure at CBD have a similar effect. They could shift the choice of the car + subway alternative from $35 \%$ to almost $90 \%$ of users. This record shows that users choice could be influenced through an adequate price policy.

Table 3: $\quad$ Model 3.

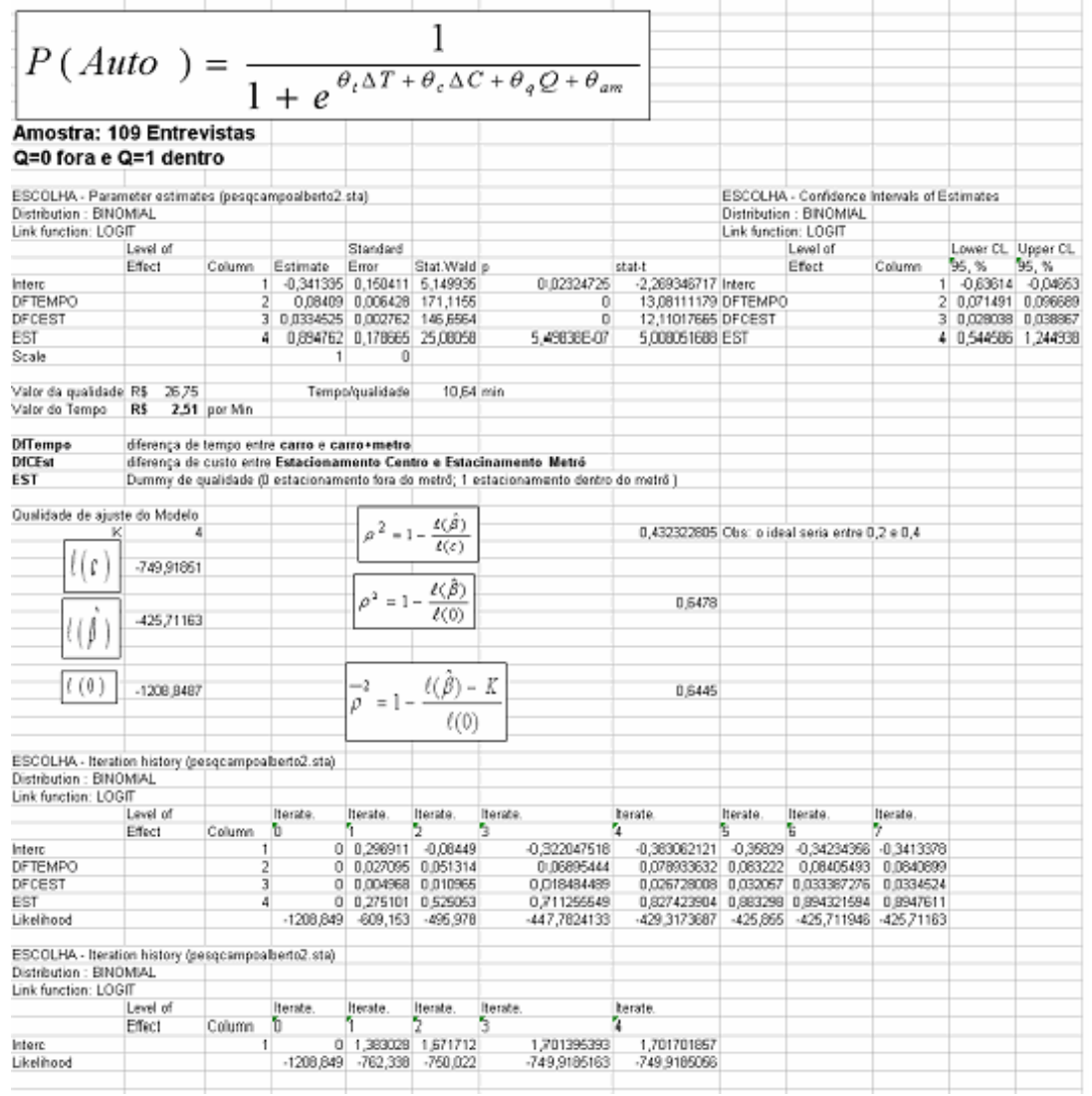

$$
\begin{aligned}
& \text { Dummy de qualidade } \\
& P(\text { Auto })=\frac{1}{1+e^{0,084 \Delta T+0,033 \Delta C+0,895 Q-0,341}}
\end{aligned}
$$


- For Model 1: considering the same total travel time and parking price differences, for each $\mathrm{R} \$ 1,00$ increase in parking prices at the $\mathrm{CBD}$, an increase of $0,6 \%$ in car + subway choice would be expected;

- For Models 1 and 2: parking inside the subway station building has a stronger influence on users' decision making towards the car + subway trip;

- For Model 3: if an urban toll was to be implemented in the city, at an average monthly cost of R $\$ 40,00$ (US\$ 25.00) for the car driver, car + subway trips would increase three times;

- For all models: total travel time differences are the strongest factor affecting users' decision making;

- There are many examples of good practices oriented towards the control of parking spaces, in order to improve the economy and cultural living of urban central areas and also to regain spaces for public transport and pedestrians. One of these practices is dedicated car parking areas, where drivers leave their vehicles and complete their trip by public transport. This practice has been recommended when the goal is both decreasing traffic jams and increasing public transport productivity. Parking restrictions downtown must follow and such parking lots should be located in less dense areas, have easy connections with public transport and a reliable and visible information service to potential users.

\section{References}

[1] CMSP - Companhia do Metropolitano de S. Paulo, O/D Survey and other data, São Paulo, 2002.

[2] Lima, A.B., Viagens park and ride por motivo trabalho - Estudo de caso na cidade de São Paulo, MSc Dissertation, Escola Politécnica da Universidade de São Paulo, São Paulo, 2007.

[3] Williams, H.C. On the formation of travel demand models and economic measures of user benefit, Environment and Planning 9A, p. 285 - 344, 1977.

[4] Ortuzar, J.D., Modelling Transport, $3^{\text {rd }}$. ed., John Willey \& Sons, New York, 2002. 